\title{
Comparison of the effects of different-sized airways in inspiratory trainers on maximal inspiratory pressure and rating of perceived exertion scale in healthy young people
}

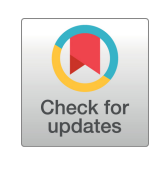

\author{
Young-In Hwang, Ki-Song Kim \\ Department of Physical Therapy, Hoseo University, Asan, Republic of Korea
}

Objective: This study aimed to investigate the effect of different-sized airways of the inspiratory muscle trainer (IMT) on maximal inspiratory pressure (MIP) and the rating of perceived exertion, as measured by the modified Borg scale (m-Borg).

Design: Cross-sectional study.

Methods: Twenty healthy subjects (10 men, 10 women) volunteered for the study. The spirometry was used to measure MIP. The trial order of the three spirometry conditions was chosen randomly. After measuring the MIP and before taking the final break, each of the conditions were immediately measured using the m-Borg. All subjects used the IMT with an airway diameter of 5-, 6-, and 7-mm.

Results: The MIP significantly decreased with the decreasing airway diameter of the IMT $(p<0.001)$, and the differences in all three conditions (7- and 6-mm, 6- and 5-mm, and 7- and 5-mm airways) were significant $(p<0.05)$. The RPE significantly increased with the decreasing airway diameter of the IMT $(p<0.001)$, and the differences in all three conditions (7- and 6-mm, 6- and 5-mm, and 7- and 5-mm airways) were significant $(p<0.05)$.

Conclusions: Decreasing the airway diameter of the IMT decreased the MIP and increased the m-Borg. In regards to physical exercise within the clinical setting, the m-Borg could be a useful as a prior monitoring method to prevent dyspnea for patients with narrowed airways (blocked with secretion or sputum in pulmonary disease) and the different-sized airways of the IMT could be applied as a useful tool to improve MIP for prevention of pulmonary disease.

Key Words: Airway resistance, Maximal respiratory pressures, Pulmonary ventilation

\section{Introduction}

The rapid industrialization of the Korean society and aging of the population has elevated the incidence of respiratory diseases and its effects on the public health [1]. Pulmonary rehabilitation is a multidisciplinary field, and included in the multiple specialists involved, the role of physical therapists is critical for improving subjects' mobility and physical strength [2].

Physical therapists are healthcare professionals who enable individuals to demonstrate their maximum physical ability by assessing their physical functions and providing individualized interventions for their problems. A physical therapist's greatest interest is on how well the subject moves, how well the therapist is able to help the patient move, and ultimately in how well the subject can execute daily living activities through motor learning [3].

If a subject encounters breathing difficulties during pulmonary rehabilitation because the physical therapist did not grasp the level of resistance and perceived exertion felt by the patient, the physical therapist would have difficulty forming a good rapport with the patient. To understand these factors, it would be useful to examine the load on the inspiratory muscle and perceived exertion at inspiration amid

Received: 12 February, 2018 Revised: 8 March, 2018 Accepted: 11 March, 2018

Corresponding author: Young-In Hwang (ORCID http://orcid.org/0000-0002-7314-1678)

Department of Physical Therapy, Hoseo University, 20 Hoseo-ro 79beon-gil, Baebang-eup, Asan 31499, Republic of Korea Tel: 82-41-540-9973 Fax: 82-41-540-9975 E-mail: eva1223@naver.com

(c) This is an Open-Access article distributed under the terms of the Creative Commons Attribution Non-Commercial License (http://creativecommons.org/licenses/ by-nc/4.0) which permits unrestricted non-commercial use, distribution, and reproduction in any medium, provided the original work is properly cited.

Copyright $@ 2018$ Korean Academy of Physical Therapy Rehabilitation Science 
increased airway resistance caused by airway secretions [4]. However, there has been no report on the effects of airflow resistance caused by changes of airway diameter during inspiration on maximal inspiratory pressure (MIP) and rating of perceived exertion [5].

Therefore, this study aims to investigate the effects of different-sized airways of the inspiratory muscle trainer (IMT) on MIP and the rating of perceived exertion in healthy adults, as measured by the modified Borg scale (m-Borg). Ultimately, this study attempts to understand the position of individuals with respiratory disease undergoing pulmonary rehabilitation and to provide reference data pertaining to the setting of appropriate exercise intensity in consideration of perceived exertion for rehabilitative exercise therapy. This study hypothesized that the "MIP and m-Borg will change in relation to the changes of the airway diameter of the IMT."

\section{Methods}

At Hoseo University (located in Asan, Chungnam Province), 20 healthy young people were recruited through a public announcement and voluntarily enrolled in the study after being adequately informed of the details of the study. This study was approved by the Institutional Review Board at Hoseo University (IRB No. 104123-170904-HR-063-02). The participants' general characteristics are shown in Table 1.

To measure MIP, the spirometer, Pony FX MIP/MEP (Cosmed Srl, Rome, Italy) [6], and a POWER breathe Try Safe Filter mouthpiece that included a sterilized gauze were used. The chosen IMT (Inspiratory Muscle Trainer; Smith

Table 1. Characteristics of subjects

\begin{tabular}{lc}
\hline \multicolumn{1}{c}{ Characteristic } & Value \\
\hline Sex & \\
$\quad$ Male & $10(50)$ \\
Female & $10(50)$ \\
Physical characteristic & \\
Age $(\mathrm{y})$ & $20.9(1.1)$ \\
Height $(\mathrm{cm})$ & $168.0(7.9)$ \\
Weight $(\mathrm{kg})$ & $65.8(9.2)$ \\
Body mass index $\left(\mathrm{kg} / \mathrm{m}^{2}\right)$ & $23.3(1.5)$ \\
Lung capacity & \\
Forced vital capacity $(\mathrm{L})$ & $4.6(0.7)$ \\
Forced expiratory volume in $1 \mathrm{~second}(\mathrm{~L})$ & $3.9(0.6)$ \\
Maximal inspiratory pressure $\left(\mathrm{cm} / \mathrm{H}_{2} \mathrm{O}\right)$ & $93.7(25.0)$ \\
\hline
\end{tabular}

Values are presented as $\mathrm{n}(\%)$ or mean (SD).

BMI: body mass index, FVC: forced vital capacity, FEV1: Forced expiratory volume in 1 second, MIP: maximal inspiratory pressure.
Medical Inc., Minneapolis, MN, USA) had diameter options of $7 \mathrm{~mm}, 6 \mathrm{~mm}$, and $5 \mathrm{~mm}$, and the diameter was adjusted using the resistive tips (Figure 1) [7]. MIP was measured at each diameter, and perceived exertion was measured using the m-Borg [8].

The participants wore comfortable clothing without outerwear and sat on a chair in an indoor laboratory with a temperature of $24^{\circ} \mathrm{C}$ and were given an explanation about the process of measuring MIP. After placing the nose clip, the participants bit on the mouthpiece and familiarized themselves with the process by following the instructions of, "take a deep breath and breath out as strong as possible for six seconds" (Figure 2) [9]. After the familiarization process, the participants were provided with a three-minute break. MIP was measured three times, after which MIP was measured. A one-minute break was taken between measurements so participants could recover to a normal breathing pattern. The median value was used for the data.

The resistance tip and mouthpiece containing a sterile gauze was used to measure MIP. MIP was measured three times by adjusting the diameter of the trainer by inserting a tip on the corresponding diameter $(7 \mathrm{~mm}, 6 \mathrm{~mm}$, and $5 \mathrm{~mm}$ ) between the mouthpiece and inspiratory muscle measurement device. The order of the three conditions was chosen randomly, and the participants rested for at least one minute between each measurement to recover normal breathing. After measuring the MIP and before taking the final break, the $\mathrm{m}$-Borg in each of the conditions was immediately measured.

The independent variable of this study was airway resistance, and the dependent variables were MIP and m-Borg.

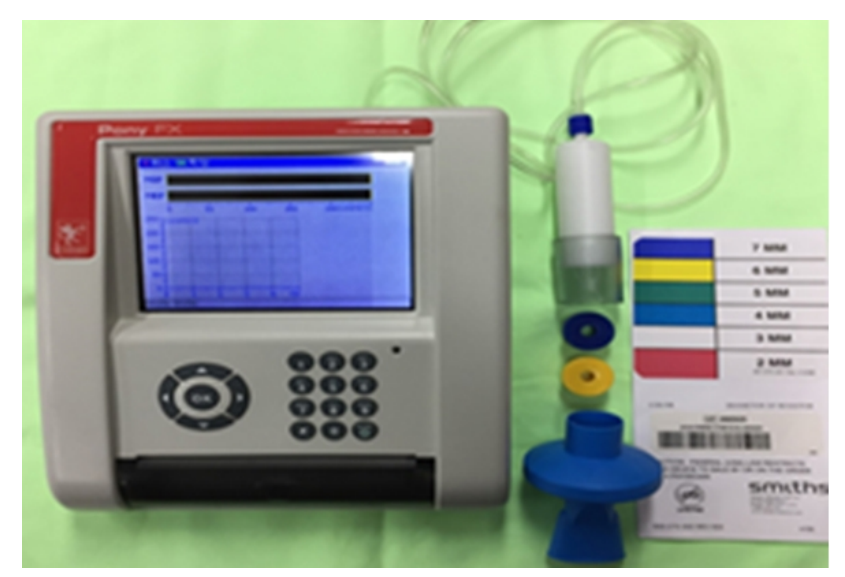

Figure 1. Spirometer, Pony FX MIP/MEP (Cosmed Srl, Rome, Italy). 
The collected data was analyzed using IBM SPSS Statistics ver. 20.0 (IBM Co., Armonk, NY, USA), and statistical significance was tested using repeated measures one-way ANOVA. The Bonferroni's correction was used as the post-hoc test, and statistical significance was set to $\alpha<0.05$.

\section{Results}

\section{Changes of maximal inspiratory pressure}

The MIP significantly decreased with the decreasing diameter of the IMT ( $p<0.001$; Table 2$)$, and the Bonferroni's correction revealed that all differences (between $7 \mathrm{~mm}$ and 6 $\mathrm{mm}$, between $6 \mathrm{~mm}$ and $5 \mathrm{~mm}$, and between $7 \mathrm{~mm}$ and 5 $\mathrm{mm})$ were significant $(p<0.001)$.

\section{Changes of perceived exertion}

RPE significantly increased with the diameter of the IMT

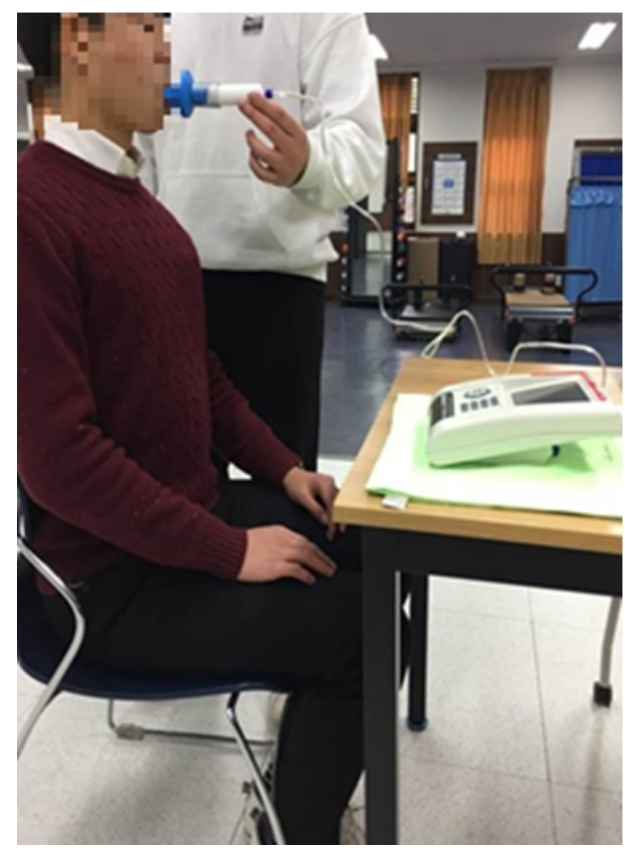

Figure 2. Maximal inspiratory pressure test in sitting position. $(p<0.001$; Table 2), and Bonferroni's correction revealed that all differences (between $7 \mathrm{~mm}$ and $6 \mathrm{~mm}$, between $6 \mathrm{~mm}$ and $5 \mathrm{~mm}$, and between $7 \mathrm{~mm}$ and $5 \mathrm{~mm}$ ) were significant $(p<0.001)$.

\section{Discussion}

This study aimed to investigate how MIP and m-Borg are altered in relation to the diameter of the IMT. The results showed that MIP significantly decreased while m-Borg significantly increased with decreasing the airway diameter of the IMT. Based on these results, our hypothesis was supported.

Hulzebos et al. [10] suggest that inspiratory muscle training before surgery prevents postoperative pulmonary complications. Dall'Ago et al. [11] also insist that inspiratory muscle training increases the MIP to $115 \%$, the peak oxygen uptake to $17 \%$, and the 6-min walk distance. In addition, some authors suggest that it improves blood flow to the resting and exercising limbs after a 4-week program in patients with weakness of inspiratory muscles [12] and so it should be used with a different-sized airway of the IMT as airway resistance of inspiratory muscle training for prevention of pulmonary disease.

On the other hand, airway resistance is the greatest factor in decreased ventilation in patients with chronic obstructive pulmonary disease (COPD) [13]. Airway clearance is also the ultimate goal of pulmonary rehabilitation for COPD patients to reduce airway resistance. In this study, decreasing the diameter of the IMT from 7 to $5 \mathrm{~mm}$ decreased the MIP by about $25 \%$. Although the decrease of MIP was not proportionate to the decrease of the airway area, this result shows that reducing the diameter of the IMT increases the difficulty of promoting an adequate influx of air into the alveoli for appropriate ventilation by decreasing the MIP.

Resting alveolar ventilation should be $4 \mathrm{~L} / \mathrm{min}$ and volume of blood flow through the pulmonary capillaries should

Table 2. Changes of different-sized airways on MIP and m-Borg

$(\mathrm{N}=20)$

\begin{tabular}{lccrc}
\hline \multirow{2}{*}{ Variable } & \multicolumn{3}{c}{ Different-sized airways } & F $(p)$ \\
\cline { 2 - 4 } & $7 \mathrm{~mm}$ & $6 \mathrm{~mm}$ & $5 \mathrm{~mm}$ & $117.403(<0.001)$ \\
$\mathrm{nyIP}\left(\mathrm{cm} / \mathrm{H}_{2} \mathrm{O}\right)$ & $84.34(21.81)^{\mathrm{a}}$ & $72.53(16.46)^{\mathrm{a}}$ & $63.15(14.18)^{\mathrm{a}}$ & $147.559(<0.001)$ \\
m-Borg & $0.75(0.47)^{\mathrm{a}}$ & $2.30(0.47)^{\mathrm{a}}$ & $3.80(0.70)^{\mathrm{a}}$ & 1400 \\
\hline
\end{tabular}

Values are presented as mean (SD).

MIP: maximal inspiratory pressure, m-Borg: modified Borg scale.

${ }^{a}$ Significant difference between different-sized airway of IMT. 
be $5 \mathrm{~L} / \mathrm{min}$ for proper ventilation [14]. Gas exchange occurs most efficiently at this ratio of ventilation/blood flow (4/5; 0.8) [14]. Patients with COPD are in critical need of fresh air with high oxygen partial pressure because their functional residual capacity is increased from an overexpansion of the lower airway [15].

Elevated airway resistance as a result of the decreased diameter of the IMT adds a greater resistance to the inspiratory muscle that has an insufficient oxygen supply, where fatigue resulting from chronic overuse of the inspiratory muscle adds to the metabolic action, further increasing the ventilation debt and aggravating breathing difficulty [16]. In our study, decreasing the diameter of the IMT significantly lowered MIP and significantly increased $\mathrm{m}$-Borg. This finding suggests that participants are more sensitive to perceived exertion when they must strive to reach the MIP for proper ventilation. In the end, airway clearance must be prioritized to emerge out of the vicious cycle and increase ventilation efficiency to lower perceived exertion (breathing difficulty) [15]. Such effort leads to muscle fatigue over time, and the inspiratory muscles and accessory inspiratory muscles are persistently in a taut state due to overuse [16-18], aggravating postural tension and pain, which intensifies anxiety and fear of breathing difficulty [19]. Therefore, airway clearance should also be the priority for COPD patients to alleviate postural tension and pain. In this context, studying more effective physical therapy interventions to promote airway clearance is crucial for physical therapists.

This study has the following limitations. First, the data were not obtained from patients with a respiratory disease, which limits the generalization of the findings. Patients with respiratory diseases not only have problems such as airway resistance due to a narrowed airway but also have problems involving compliance, such as thoracic cage deformity or compositional changes of respiratory muscle due to chronic fatigue. When reduced compliance is combined with airway resistance, perceived exertion may rise more steeply compared to normal people, even when performing physical activities of the same exercise intensity. In the present study, we could not measure changes of perceived exertion that reflected these problems faced by actual patients with respiratory diseases. Second, inspirational muscle activity was not measured. We did not investigate how increased airway resistance affects muscle activity; thus, we could not present data that would help set appropriate exercise intensity by comparing the muscle use data with our findings. Third, data during physical activity could not be measured, so we do not know how the increased airway resistance caused by decreasing the diameter of the IMT would have affected perceived exertion in real life activities.

In this study, decreasing the diameter of an IMT decreased MIP and increased m-Borg significantly. Because patients are more sensitive to airway resistance caused by airway narrowing in terms of perceived discomfort or exertion as opposed to developing symptoms of breathing difficulty as a result of elevated burden on the inspiratory muscles, physical therapists should monitor patients using the m-Borg when setting exercise intensity during exercise therapy for pulmonary rehabilitation. Furthermore, the different-sized airway of the IMT also would be applied a useful tool to improve MIP for prevention of pulmonary disease.

\section{Conflict of Interest}

The authors declared no potential conflicts of interest with respect to the authorship and/or publication of this article.

\section{References}

1. Yoon HK, Park YB, Rhee CK, Lee JH, Oh YM. Summary of the chronic obstructive pulmonary disease clinical practice guideline revised in 2014 by the Korean Academy of Tuberculosis and Respiratory Disease. Tuberc Respir Dis 2017;80:230-40.

2. Kang MG, Song WJ, Kim HJ, Won HK, Sohn KH, Kang SY, et al. Point prevalence and epidemiological characteristics of chronic cough in the general adult population: the Korean National Health and Nutrition Examination Survey 2010-2012. Medicine 2017;96:e6486.

3. Sanchez RJ, Liu J, Rao S, Shah P, Smith R, Rahman T, et al. Automating arm movement training following severe stroke: functional exercises with quantitative feedback in a gravity-reduced environment. IEEE Trans Neural Syst Rehabil Eng 2006; 14:378-89.

4. McConnell A. Respiratory muscle training: theory and practice [E-book]. London: Elsevier Health Sciences; 2013.

5. Enright SJ, Unnithan VB, Heward C, Withnall L, Davies DH. Effect of high-intensity inspiratory muscle training on lung volumes, diaphragm thickness, and exercise capacity in subjects who are healthy. Phys Ther 2006;86:345-54.

6. Cavalheri V, Camillo CA, Brunetto AF, Probst VS, Ramos EM, Pitta F. Effects of arm bracing posture on respiratory muscle strength and pulmonary function in patients with chronic obstructive pulmonary disease. Rev Port Pneumol 2010;16:887-91.

7. Amarsheda S, Bhise AR, Patel SG. Efficacy of inspiratory muscle trainer and incentive spirometer on inspiratory muscle strength in patients with tetraplegia in Indian setting. Arch Phys Med Rehabil 2016;97:e49.

8. Kim YS, Shin J, Choi YJ, Song JH, Lee JK, Oh HL, et al. Comparison on the profiles of a modified Borg scale and the pe- 
diatric dyspnea scale during an induced bronchoconstriction in children with clinical asthma. Allergy Asthma Respir Dis 2017; 5:262-8.

9. Miller MR, Hankinson J, Brusasco V, Burgos F, Casaburi R, Coates A, et al. Standardisation of spirometry. Eur Respir J 2005; 26:319-38.

10. Hulzebos EH, Helders PJ, Favié NJ, De Bie RA, Brutel de la Riviere A, Van Meeteren NL. Preoperative intensive inspiratory muscle training to prevent postoperative pulmonary complications in high-risk patients undergoing CABG surgery: a randomized clinical trial. JAMA 2006;296:1851-7.

11. Dall'Ago P, Chiappa GR, Guths H, Stein R, Ribeiro JP. Inspiratory muscle training in patients with heart failure and inspiratory muscle weakness: a randomized trial. J AM Coll Cardiol 2006; 47:757-63.

12. Chiappa GR, Roseguini BT, Vieira PJ, Alves CN, Tavares A, Winkelmann ER, et al. Inspiratory muscle training improves blood flow to resting and exercising limbs in patients with chronic heart failure. J AM Coll Cardiol 2008;51:1663-71.

13. Leeman M, Lejeune P, Melot C, Naeije R. Reduction in pulmo- nary hypertension and in airway resistances by enoximone (MDL 17,043) in decompensated COPD. Chest 1987;91:662-6.

14. West JB. Respiratory physiology: the essentials. Baltimore, MD: Lippincott Williams \& Wilkins, a Wolters Kluwer Business; 2012.

15. Tout R, Tayara L, Halimi M. The effects of respiratory muscle training on improvement of the internal and external thoracopulmonary respiratory mechanism in COPD patients. Ann Phys Rehabil Med. 2013;56:193-211.

16. Similowski T, Yan S, Gauthier AP, Macklem PT, Bellemare F. Contractile properties of the human diaphragm during chronic hyperinflation. N Engl J Med 1991;325:917-23.

17. Ides K, Vissers D, De Backer L, Leeman G, De Backer W. Airway clearance in COPD: need for a breath of fresh air? A systematic review. COPD 2011;8:196-205.

18. O'Donnell DE. Dynamic lung hyperinflation and its clinical implication in COPD. Rev Mal Respir 2008;25:1305-18.

19. Delplanque D. La charge de travail ventilatoire chez le BPCO. Kinesither Sci 2001;417:50-3. 